\title{
ARTIGO ORIGINAL \\ Notícias da Escola de Enfermagem Wenceslau Braz através da imprensa escrita pública nos anos de 1954 a 1958
}

Adrieli de Fátima Teixeira Guimarães*, Waldere Fabri Pereira Ribeiro, D.Sc.**, Cláudia Alessandra Pereira Paixão, M.Sc.***

*Bolsista do Programa de Iniciação Científica, Discente do curso de enfermagem da Faculdade Wenceslau Braz, Itajubá MG, ${ }^{\star \star}$ Enfermeira, Faculdade Wenceslau Braz, Itajubá MG ${ }^{* \star \star}$ Docente na Faculdade Wenceslau Braz, Itajubá MG

Recebido em 13 de julho de 2017; aceito em 30 de abril de 2018.

Endereço para correspondência: Cláudia Alessandra Pereira Paixão, Avenida Cesário Alvim, 566, centro, 37501-059 Itajubá MG, E-mail: claapp2@gmail.com; Adrieli de Fátima Teixeira Guimarães: adrieli_guimaraes@yahoo.com; Waldere Fabri Pereira Ribeiro: walfabri@gmail.com

\section{Resumo}

Pesquisa de cunho histórico-social objetivou identificar os jornais que contém notícias da Escola de Enfermagem Wenceslau Braz (EEWB) entre os anos de 1954 e 1958, em relação à cidade e data de impressão e descrever as notícias. O objeto foi as notícias sobre a EEWB publicadas na imprensa escrita pública a época. O local foi a EEWB. O recorte temporal englobou o marco inicial (1954) criação da EEWB e o final (1958) formatura da primeira turma. Os dados foram obtidos através da análise de fontes: 1) primárias: 40 recortes de jornais que continham notícias da EEWB, pertencentes ao acervo pessoal da professora Waldere Fabri Pereira Ribeiro; e 2) secundárias: livros, teses e estudos que abordavam a imagem social, identidade da enfermeira, a evolução dos meios de comunicação escrita, história da Enfermagem e ensino da Enfermagem no Brasil. A análise do documento jornalístico foi um roteiro composto de três partes sendo: identificação do recorte levando em consideração o seu arquivamento; análise técnica; análise propriamente dita do documento e articulação da mesma com as questões pertinentes. Os resultados demonstraram a importância das notícias através da imprensa escrita pública à época, para a divulgação da nova instituição, com o intuito de recrutamento de novas candidatas. Evidenciou-se que as notícias foram publicadas em diversos jornais da região sul-mineira. Conclui-se que o estudo possibilitou alcançar os objetivos inicialmente propostos e responder todas as indagações, bem como conhecer as notícias publicadas acerca de uma escola de Enfermagem e sua relação com a história do ensino da Enfermagem no Brasil.

Palavras-chave: história da enfermagem, escolas de enfermagem, artigo de jornal.

\section{Abstract \\ News from the Escola de Enfermagem Wenceslau Braz through the public writing press in the years from 1954 to 1958}

This research of social-historical nature aimed to identify newspapers with news of the Escola de Enfermagem Wenceslau Braz (EEWB) between 1954 and 1958, in relation to the city and date of printing and describe the news. The aim was the news about the EEWB published in the written press during this period. The place was the EEWB. The specific time encompassed the starting point (1954) EEWB creation and the final point (1958) graduation of the first class. The data were obtained through the analysis of sources: 1) primary: 40 newspaper clippings with EEWB news, which belong to the personal collection of Professor Waldere Fabri Pereira Ribeiro and; 2) secondary: books, theses and studies that addressed the social image, nurse identity, the evolution of print media, nursing history and nursing teaching in Brazil. The analysis of the journalistic document was a roadmap composed of three parts: identification of the specific time taking into account its filing; technical analysis; analysis properly of the document and its articulation with the pertinent questions. The results demonstrated the importance of news through the print press at the time, for the new institution, with the intention of recruiting new candidates. It was evidenced that the news was published in several newspapers of the state. It was concluded that the study made it possible to reach the objectives initially proposed and all 
inquiries, as well as to know the published news about a school of nursing and its relation with the history of nursing teaching in Brazil.

Key-words: history of nursing, schools nursing, newspaper article.

\section{Resumen \\ Noticias de la Faculdade de Enfermagem Wenceslau Braz a través de la prensa escrita pública nos años de 1954 a 1958}

Investigación de cuño histórico-social que objetivó identificar los periódicos que contienen noticias de la Faculdade de Enfermagem Wenceslau Braz (EEWB) entre los años de 1954 y 1958, en relación a la ciudad y fecha de impresión y describir las noticias. El objeto fue las noticias sobre la EEWB publicadas en la prensa escrita pública de la época. El lugar fue el EEWB. El recorte temporal englobó el marco inicial (1954) creación de la EEWB y el final (1958) graduación de la primera clase. Los datos fueron obtenidos a través del análisis de fuentes: 1) primarias: 40 recortes de periódicos que contenían noticias de la EEWB, que pertenecen a la profesora Waldere Fabri Pereira Ribeiro; y 2) secundarias: libros, tesis y estudios que abordan la imagen social, identidad de la enfermera, la evolución de los medios de comunicación escrita, historia de la enfermería y enseñanza de la Enfermería en Brasil. El análisis del documento periodístico fue un guión compuesto de tres partes siendo: identificación del recorte teniendo en cuenta su archivo; análisis técnico; el análisis propiamente dicho del documento y la articulación de la misma con las cuestiones pertinentes. Los resultados demostraron la importancia de las noticias a través de la prensa escrita pública en la época, para la divulgación de la nueva institución, con el propósito de reclutamiento de nuevas candidatas. Se evidenció que las noticias fueron publicadas en diversos diarios de la región minera sureña. Se concluye que el estudio posibilitó alcanzar los objetivos inicialmente propuestos y responder todas las indagaciones, así como conocer las noticias publicadas acerca de una facultad de enfermería y su relación con la historia de la enseñanza de la enfermería en Brasil.

Palabras-clave: historia de enfermería, facultades de enfermería, artículo de periódico.

Introdução

A história da criação da Escola de Enfermagem Wenceslau Braz (EEWB), hoje denominada Faculdade Wenceslau Braz, iniciou-se com a sua fundação em 9 de janeiro de 1954, "pela Santa Casa de Misericórdia de Itajubá, conforme ata da reunião da Mesa Administradora dessa entidade..." [1].

Quando foi aprovada a ideia da criação de uma escola de Enfermagem, em 1954, religiosas enfermeiras da Congregação das Irmãs da Providência de Gap (CIPG) atuavam com profissionais da saúde na Santa Casa de Misericórdia de Itajubá (SCMI) e uma delas administrava a mesma. Desta forma a CIPG providenciou para que uma religiosa educadora tomasse as primeiras providências para a instalação de uma escola de Enfermagem em concordância com as exigências do Ministério da Educação e Cultura. Desta forma em 23 de setembro de 1954 é publicado no Diário Oficial da União a Portaria Ministerial № 854 que autorizava o funcionamento da instituição. Em março de 1955 inicia-se o funcionamento da EEWB, com a aula inaugural proferida pelo Dr. Gaspar Lisboa, membro do corpo clínico da SCMI e do corpo docente da nova instituição de ensino [1].

A CIPG preocupada em formar enfermeiras competentes enviou, antes do início do funcionamento da escola, duas religiosas enfermeiras que atuavam na SCMI para, como futuras professoras da escola, realizarem um estágio na Escola de Enfermagem Anna Nery, considerada como escola oficial padrão, na então capital federal, Rio de Janeiro, a fim de adquirirem conhecimento sobre a organização e o funcionamento de uma escola de Enfermagem, de modo a se prepararem para ocupar dois dos diferentes cargos da nova instituição de ensino: uma para o cargo de diretora e a outra para o cargo de professora da disciplina "Enfermagem em Cirurgias" e "Técnicas de Enfermagem". Uma delas ainda retornaria no ano de 1956 ao Rio de Janeiro para estudar Psicologia e Saúde Pública na referida escola de Enfermagem [2].

Ribeiro [2] afirma que vale recordar que, em 1931, ocorreu a regulamentação do exercício da Enfermagem no país e foram fixadas as condições para a equiparação das demais escolas de Enfermagem existentes, ou a serem criadas, à Escola de Enfermagem Anna Nery que era na época considerada a escola oficial padrão, o que institucionalizou o Padrão Ana Neri (PAN) de formação, um alicerce para a configuração da identidade da enfermeira brasileira. Isto se deve ao fato de que fazem parte do legado da Missão de Enfermeiras Norte- 
americanas que, em 1923, trouxeram para o Brasil, os instrumentos legais que asseguraram a institucionalização do ensino e da prática da Enfermagem nos moldes nightingaleanos.

Nos primeiros anos de seu funcionamento a EEWB procurou não só chamar a atenção da sociedade itajubense sobre a escola de Enfermagem criada na cidade, como também dar transparência para o curso de Enfermagem, assim divulgavam a escola. A divulgação ocorria em publicações de notícia em jornais não só da cidade como também das cidades circunvizinhas. Também levava as alunas a participar, devidamente uniformizadas, de eventos sociais e culturais, com o objetivo de atrair novas alunas de acordo com que desejavam [2].

Sabemos que o jornal é um meio de comunicação bastante antigo que divulga informações de várias formas e com vários objetivos. As informações procuram ser verídicas com descrição de detalhes que esclareça quaisquer dúvidas que possam ocorrer.

Um jornal serve para divulgar notícias de diferentes teor. A notícia pode despertar atitudes, visto que as notícias na maioria das vezes estão veiculadas a cultura, pensamentos de uma sociedade [3].

Para Cereja e Cochar [4], a notícia expressa divulga um fato novo, uma novidade opinando sobre o mesmo. Geralmente a novidade desperta o interesse do público-alvo.

\section{Material e métodos}

O objeto foi as notícias sobre a EEWB publicadas na imprensa escrita publica a época. O local foi a EEWB. O recorte temporal englobou o marco inicial (1954) criação da EEWB e o final (1958) formatura da primeira turma. Os dados foram obtidos através da análise de fontes: 1) primárias: 40 recortes de jornais que continham notícias da EEWB, que pertenciam ao acervo pessoal da professora Waldere Fabri Pereira Ribeiro; e 2) secundárias: livros, teses e estudos que abordam a imagem social, identidade da enfermeira, a evolução dos meios de comunicação escrita, história da enfermagem e ensino da Enfermagem no Brasil. A análise do documento jornalístico foi um roteiro composto de três partes sendo: identificação do recorte levando em consideração o seu arquivamento; análise técnica; análise propriamente dita do documento e articulação da mesma com as questões pertinentes.

Foi realizado um estudo de cunho histórico-social cujos objetivos foram: identificar os jornais que contém notícias da EEWB no período entre os anos de 1954 e 1958, em relação à cidade e data de impressão e; descrever as notícias da EEWB publicadas nos jornais no período acima referido em relação ao objetivo de publicação. Para tanto foram pesquisadas notícias em jornais do município de Itajubá, MG e de regiões circunvizinhas sobre a instituição.

Resultados

Foram encontradas 40 fontes pertencentes ao período do estudo e analisadas em duas etapas: 1) Identificação dos jornais que contém notícias da EEWB no período do estudo em relação à cidade e ano de impressão; 2) Descrição das notícias da EEWB publicadas nos jornais em questão.

Os resultados demonstraram a importância das notícias através da imprensa escrita pública à época, para a divulgação da nova instituição, com o intuito de recrutamento de novas candidatas. Evidenciou-se que as notícias foram publicadas em diversos jornais da região sulmineira.

Das 40 fontes encontradas apenas 1 era do ano de 1954. Este é o jornal "Diário de Poços de Caldas" que apresenta como título da notícia: Uma Escola de Enfermagem na Região sul-mineira [11].

Duas fontes datavam 1955. Uma delas, o jornal "O Sul de Minas" [12], trazia 5 notícias sobre a EEWB, três trazendo como destaque a aula inaugural proferida pelo Dr. Gaspar Lisboa, e as outras duas notícias eram uma sobre a semana da enfermeira e sobre uma contribuição financeira que o Estado havia doado a esta instituição de ensino.

A outra fonte do ano de 1955 foi o jornal a "Gazeta" da cidade de Ouro Fino [13], Sul de Minas Gerais, que publicou uma notícia, com o teor de propaganda.

Em relação ao ano de 1956 foram encontradas 19 fontes de jornais de cidades circunvizinhas do sul de Minas que apresentaram como notícia uma propaganda da EEWB. 
Quadro 1 - Jornais com notícias da EEWB no período de 1954 a 1958 em relação ao nome, cidade e ano de impressão.

\begin{tabular}{|l|c|c|c|}
\hline \multicolumn{1}{|c|}{ Jornal } & Cidade & Ano & $\begin{array}{c}\text { Notícias } \\
\text { Publicadas }\end{array}$ \\
\hline Diário de Poços de Caldas & Poços de Caldas & 1954 & 1 \\
\hline O Sul de Minas & Itajubá & 1955 & 5 \\
\hline Gazeta & Ouro Fino & 1955 & 1 \\
\hline Correio do Sul & Ouro Fino & 1956 & 1 \\
\hline Gazeta & Santa Rita do Sapucaí & 1956 & 1 \\
\hline A janela & Brasópolis & 1956 & 1 \\
\hline O Sul de Minas & Itajubá & 1956 & 6 \\
\hline O popular & Andradas & 1956 & 1 \\
\hline A gazeta de Jacutinga & Jacutinga & 1956 & 1 \\
\hline Correio da manhã & Caxambu & 1956 & 1 \\
\hline A cidade & Pouso Alegre & 1956 & 1 \\
\hline Correio do sul & Santa Rita do Sapucaí & 1956 & 1 \\
\hline A opinião & São Gonçalo do Sapucaí & 1956 & 1 \\
\hline Gazeta & Ouro Fino, & 1956 & 1 \\
\hline A janela & Brasópolis & 1956 & 1 \\
\hline Jornal Sul de Minas & Varginha & 1956 & 1 \\
\hline Voz Cristinense & Cristina & 1956 & 1 \\
\hline O Sul de Minas & Itajubá & 1957 & 5 \\
\hline O Sul de Minas & Itajubá & 1958 & 2 \\
\hline A janela & Brasópolis & 1958 & 1 \\
\hline A janela & Brasópolis & {$[195 ?]$} & 1 \\
\hline Jornal de Paraisópolis & Paraisópolis & {$[195 ?]$} & 1 \\
\hline Gazeta & Ouro Fino & {$[195 ?]$} & 1 \\
\hline Jornal Sul de Minas & Varginha & {$[195 ?]$} & 1 \\
\hline A janela & Brasópolis & {$[195 ?]$} & 1 \\
\hline O Sul de Minas & Itajubá & {$[195 ?]$} & 1 \\
\hline
\end{tabular}

A primeira fonte encontrada com a data deste ano de 1956 foi o jornal "Voz Cristinense de Cristina" [14] que destacou a inauguração da Escola de Enfermagem de Itajubá. Foram encontradas seis notícias no ano de 1956 sobre a escola no jornal "O Sul de Minas [15]" sendo estas: a segunda aula inaugural; visita de três representantes do Ministério da Educação e Cultura; uma propaganda; um agradecimento aos médicos professores que lecionavam sem proventos; notícias da participação de alunas em congresso de enfermeiras e notícias sobre a cerimônia da entrega da touca da enfermeira à segunda turma de alunas da instituição.

Só uma fonte com a data de 1957 foi encontrada, porém com cinco publicações de notícias sobre a EEWB em semanas diferentes. Esta fonte, O Sul de Minas [16], trouxe duas notícias sobre a terceira aula inaugural; uma informava sobre o reconhecimento oficial do curso de enfermagem pela EEWB; outra sobre a formação integral de uma enfermeira; outra sobre o reconhecimento e uma última sobre admiração dos gestos de colaboração dos senhores médicos.

Em 1958 foram encontradas duas fontes diferentes, sendo o jornal "O Sul de Minas" [17] que apresentou duas manchetes: uma sobre a quarta aula inaugural e notícias sobre a formatura da primeira turma de enfermeiras e o jornal $A$ janela da cidade de Brasópolis que publicou uma notícia de propaganda sobre a EEWB.

Foi possível identificar quatro fontes com notícias já publicadas em outros jornais, porém não foi possível identificar o ano, apenas presumir de acordo com a notícia. Acreditamos que em 1958 o Jornal "A janela" publicou uma segunda edição da manchete "O Brasil precisa de enfermeiras". Os jornais das cidades de Ouro Fino, Paraisópolis, Brasópolis e Varginha, possivelmente em 1955, publicaram notícias sobre a semana da enfermeira. 


\title{
Notícias da EEWB publicadas nos jornais no período entre 1954 a 1958
}

\section{Notícias sobre a fundação da EEWB}

Foi encontrado apenas um jornal com uma notícia referente à fundação da escola.

O jornal Diário de Poços de Caldas (1954, p.01) publicou a seguinte notícia sobre a EEWB:

\begin{abstract}
ESCOLA DE ENFERMAGEM em Itajubá
Comunicamos que, em portaria n.853, de 23 de setembro 1954, o Exmo. Sr. Ministro da Educação e Cultura autorizou o funcionamento da Escola de Enfermagem Wenceslau Braz.

As aulas terão início em março próximo. As candidatas estão convidadas a se dirigirem à Diretoria da Santa Casa ou à Escola Normal de Itajubá, onde lhe serão prestadas informações a respeito de matrícula ou quaisquer outras que possam interessar.

Se você terminou seus estudos de curso secundário, se deseja uma carreira nobilitante e altamente conceituada em que, ao lado do médico, possa contribuir para alívio dos que sofrem, procure a Escola de Enfermagem Wenceslau Braz de Itajubá.
\end{abstract}

O Diário de Poços de Caldas (1954) destacou a fundação da EEWB com o objetivo de divulgação e de atrair candidatas informando como deveria ser o perfil e a personalidade das mesmas, e as exigências para a realização da matrícula; mostrando que existia uma vantagem não só para a cidade de Itajubá, mas também para toda a região sul-mineira em se ter uma escola de Enfermagem. Este jornal ainda informava aos leitores que a escola iria funcionar em anexo à SCMI, em regime de internato sob fiscalização do Ministério da Educação e Cultura, sendo seu corpo docente constituído por médicos e irmãs da Providência de GAP sendo as mesmas enfermeiras diplomadas [11].

Aula inaugural

Foram encontrados sete jornais com notícias referentes à aula inaugural.

Quadro 2 - Jornais com notícias da EEWB no período de 1954 a 1958 em relação à aula inaugural, ano, notícias publicadas, tema e palestrante.

\begin{tabular}{|c|c|l|l|l|}
\hline \multicolumn{1}{|c|}{ Jornal } & \multicolumn{1}{|c|}{ Ano } & Notícias Publicadas & \multicolumn{1}{c|}{ Tema } & \multicolumn{1}{c|}{ Palestrante } \\
\hline O Sul de Minas & 1955 & 3 & $\begin{array}{l}\text { Histórico da } \\
\text { criação da EEWB }\end{array}$ & $\begin{array}{l}\text { Prof. Dr. Gaspar } \\
\text { Lisboa }\end{array}$ \\
\hline O Sul de Minas & 1956 & 1 & $\begin{array}{l}\text { A enfermeira em } \\
\text { saúde pública }\end{array}$ & $\begin{array}{l}\text { Prof. Dr. Antônio } \\
\text { Braga Filho }\end{array}$ \\
\hline O Sul de Minas & 1957 & 2 & $\begin{array}{l}\text { Evolução dos } \\
\text { conhecimentos } \\
\text { médicos }\end{array}$ & $\begin{array}{l}\text { Prof. Dr. Carlos } \\
\text { Victor Renó Ribeiro }\end{array}$ \\
\hline O Sul de Minas & 1958 & 1 & $\begin{array}{l}\text { A medicina } \\
\text { psicossomática }\end{array}$ & $\begin{array}{l}\text { Prof. Dr. José } \\
\text { Chaiben Mauad }\end{array}$ \\
\hline
\end{tabular}

\section{Reconhecimento}

Duas edições do jornal "O Sul de Minas" publicaram notícia referente ao reconhecimento da EEWB. A primeira notícia sobre o reconhecimento da escola ocorreu no jornal O Sul de Minas no ano de 1956, que informou aos leitores que a escola recebeu a visita de três membros representando o Ministério da Educação e Cultura, com a finalidade de se realizar uma inspeção, para efeito de reconhecimento oficial da mesma [15].

No ano de 1957 foi publicado que o reconhecimento oficial do curso de Enfermagem pelo decreto do Exmo. Sr. Presidente da República de n.40.572, de 18 de dezembro e publicado no Diário Oficial no dia 10 de janeiro [16]. 
Propaganda

Foram encontrados 17 jornais com notícia que fazia propaganda da escola.

Quadro 3 - Jornais com notícias da EEWB no período de 1954 a 1958 em relação à propaganda.

\begin{tabular}{|c|c|c|c|}
\hline Jornal & Cidade & Ano & Notícias Publicadas \\
\hline Gazeta & Ouro Fino & 1955 & 1 \\
\hline Correio do Sul & Santa Rita do Sapucaí & 1956 & 1 \\
\hline Gazeta & Ouro Fino & 1956 & 1 \\
\hline A janela & Brasópolis & 1956 & 1 \\
\hline Voz Cristinense & Cristina & 1956 & 1 \\
\hline Correio do Sul & Santa Rita do Sapucaí & 1956 & 1 \\
\hline O Popular & Andradas & 1956 & 1 \\
\hline A janela & Brasópolis & 1956 & 1 \\
\hline Gazeta & Ouro Fino & 1956 & 1 \\
\hline A gazeta de Jacutinga & Jacutinga & 1956 & 1 \\
\hline Correio da manhã & Caxambu & 1956 & 1 \\
\hline Jornal Sul de Minas & Varginha & 1956 & 1 \\
\hline A cidade & Pouso Alegre & 1956 & 1 \\
\hline A opinião & São Gonçalo do Sapucaí & 1956 & 1 \\
\hline O Sul de Minas & Itajubá & 1956 & 1 \\
\hline O Sul de Minas & Itajubá & 1957 & 1 \\
\hline A janela & Brasópolis & 1958 & \\
\hline
\end{tabular}

\section{Agradecimentos}

Encontramos dois jornais cada um com uma notícia com agradecimento que EEWB faz.

O jornal O Sul de Minas (1956) publicou uma notícia em relação a agradecimentos da EEWB com o seguinte título: Louvor dos Nobres Gestos [15].

A Escola de Enfermagem Wenceslau Braz, diretoria e alunas, sentem a necessidade imperiosa de fazer público o seu agradecimento ao distinto corpo clínico da Santa Casa desta cidade, pela dedicação com que vem lecionando na escola. Levantada esta escola em meio a muitas dificuldades, naturalmente ignoradas, pudemos, desde o início contar não apenas com 0 trabalho dos Srs. Médicos, mas com uma abnegação que tem valido para as alunas como lição magna e estímulo nas lides que serão suas, na difícil missão da Enfermagem [15].

Outro agradecimento é noticiado pelo jornal "O Sul de Minas" (1957) que traz como manchete: Preito de reconhecimento e admiração, onde é publicado um agradecimento pela diretoria e as alunas da EEWB para os médicos que faziam parte do corpo docente da instituição. O agradecimento é publicado da seguinte forma [16]:

Num movimento espontâneo e incoercível, desejam fazer em públicos os seus sentimentos de gratidão e admiração aos distintos Srs. Médicos que constituem o corpo docente da Escola e cujo nome é de justiça designar: Drs. Gaspar Lisboa, Luís Pereira de Toledo, João Azevedo, Antônio Braga Filho, Pedro Rosa, João Severiano Ribeiro, José Mauad, Luiz Gonzaga Mauad, José de Araújo Barbosa, Jerson Dias, Orlando Sanches, e o Sr. Florival Xavier [16].

Semana da Enfermeira

Encontramos sete notícias em jornais que trazem como tema a semana da enfermeira.

Quadro 4 - Jornais com notícias da EEWB no período de 1954 a 1958 em relação à semana da enfermeira.

\begin{tabular}{|c|c|c|c|}
\hline Jornal & Cidade & Ano & Notícias Publicadas \\
\hline Gazeta & Ouro Fino & {$[195 ?]$} & 1 \\
\hline Jornal de Paraisópolis & Paraisópolis & {$[195 ?]$} & 1 \\
\hline
\end{tabular}




\begin{tabular}{|c|c|c|c|}
\hline A janela & Brasópolis & {$[195 ?]$} & 1 \\
\hline Jornal Sul de Minas & Varginha & {$[195 ?]$} & 1 \\
\hline O sul de Minas & Itajubá & {$[195 ?]$} & 1 \\
\hline O sul de Minas & Itajubá & 1955 & 1 \\
\hline A janela & Brasópolis & {$[195 ?]$} & 1 \\
\hline
\end{tabular}

\section{Contribuição financeira do Estado}

Foi encontrado apenas um jornal com uma notícia referente à contribuição financeira do Estado para a escola. A notícia publicada destacava:

Folheando o "Minas Gerais" de 17 de novembro p. findo, deparamos com a seguinte notícia que, com a devida vênia, passamos a transcrever: Lei N.1 323, de 16 de novembro de 1955, concede auxílio financeiro a EEWB" [12].

\section{Congresso}

Foi encontrado apenas um jornal com notícia referente à participação em congresso.

O Sul de Minas (1956, p.1) realizou uma publicação: Ecos de um congresso de enfermeiras, o qual pode ser considerado uma projeção cultural da EEWB [15].

Assim dizia:

"Realizou-se em Porto Alegre, em outubro último, um congresso de Enfermagem, a que estiveram presentes enfermeiras de todos os pontos do Brasil e de alguns países vizinhos como Argentina, Uruguai e Paraguai. O certame revestiu-se de grande significado, em vista do temário: Ensino Clínico e Código de Ética da Enfermeira" [15].

\section{Formatura da primeira turma de enfermeiras}

Foi encontrado apenas um jornal com uma notícia referente à formatura da primeira turma da EEWB. Ribeiro afirma que a solenidade de formatura da primeira turma de enfermeiras da EEWB, aconteceu no dia 9 de março de 1958, contando com cinco formandas na qual três eram leigas e as outras duas eram religiosas da congregação [2].

O acontecimento foi descrito pelo jornal "O Sul de Minas (1958)" com o título Escola de Enfermagem Wenceslau Braz, solenidade de formatura de sua primeira turma de enfermeiras [17].

\footnotetext{
"O programa dessa solenidade constou de missa celebrada às $08 \mathrm{~h} 30 \mathrm{~min}$ na capela da Santa Casa e entrega de diplomas, no Auditório da Escola Normal Sagrado Coração de Jesus, às 19 horas."
}

\section{Entrega da touca da enfermeira da segunda turma}

Foi encontrado apenas um jornal com uma notícia referente à cerimônia de entrega da touca. O primeiro rito de passagem ao qual era submetida à aluna da EEWB era o da recepção da touca, indicando que a aluna estava aprovada no estágio probatório, ou seja, que tinha obtido a aprovação na primeira etapa do curso, estando assim apta para ingressar de forma efetiva no corpo discente da escola [2].

Sabendo da importância da entrega da touca para a aluna da graduação o jornal "O Sul de Minas (1956)" publicou uma notícia em relação à entrega da touca da segunda turma da EEWB [15].

Procedeu a Escola de Enfermagem "Dr. Wenceslau Braz", às 14 horas do dia 13 do corrente, com a presença de sua diretoria, corpo discente e vários membros de seu corpo docente, pessoas das famílias das alunas e outras pessoas gradas, a cerimônia de entrega da toca da enfermeira a sua segunda turma [15]. 
Perante a realização deste trabalho e através dos objetivos que foram estabelecidos, acredita-se que foi extremamente relevante identificar os jornais que contém as notícias da EEWB no período entre os anos de 1954 e 1958, em relação à cidade e a data de sua impressão, bem como descrever as notícias da EEWB ali publicadas.

Durante o decorrer do trabalho, evidenciou-se a importância das notícias através da imprensa escrita pública à época, para a divulgação da nova instituição que estava se formando, quando as mesmas divulgavam a EEWB através de fatos ocorridos com o intuito de recrutamento de novas candidatas conforme os objetivos estabelecidos.

Através da identificação e descrição das notícias do período citado anteriormente e a busca na literatura sobre o tema, evidenciou-se também que as notícias que foram publicadas em diversos jornais da região sul-mineira ampliou a divulgação da mesma no espaço geográfico determinado, dando transparência à nova instituição de ensino que se iniciava numa cidade de interior.

A riqueza dos fatos deste estudo possibilitou atribuir ao cunho histórico a partir do momento que se fez um levantamento dos jornais que publicaram notícias da EEWB bem como a descrição das notícias passadas publicadas, sem reconstruí-las. Sendo assim, o seu intuito inicial foi atingido. Ampliou os conhecimentos sobre a história da instituição de ensino em questão e da enfermagem brasileira. Desta forma o intuito inicial foi atingido.

Este estudo, com toda a sua originalidade possibilitou descrever abertamente sobre a imagem que a EEWB procurava divulgar através de notícias no jornal da cidade bem como em jornais de cidades circunvizinhas.

Sendo um estudo original, ele nos possibilitou juntar esforços aos estudiosos da história da Enfermagem brasileira, contribuindo para estudos nesta linha de pesquisa visando à contribuição para novas explicações acerca da profissão; porém ainda existe a necessidade de se ampliar as pesquisas acerca da história da Enfermagem da EEWB no que diz respeito a outros elementos significativos para a Enfermagem.

1. Baroni D, Rosa TRO, Mansur R, Bacelar RB. O gênero textual notícia: do jornal impresso ao on-line. In: Encontro Nacional de História da Mídia, 9. 2013, Ouro Preto. [citado 2015 maio 22]. Disponível em: http://www.ufrgs.br/alcar/encontros-nacionais1/9o-encontro-2013/artigos/gt-historia-da-midia-digital/o-genero-textual-noticia-dojornal-impresso-ao-on-line.

2. Cereja WR, Cochar MTA. Português: linguagens: literatura, gramática e redação. 2. ed. rev. e ampl. São Paulo: Atual; 1994.

3. Catalão T. Para que serve um jornal. Brasília- DF. 2008. [citado 2015 Maio 20]. Disponível em: http://deolhonacapital.blogspot.com.br/2008/05/para-que-serve-umjornal.htmI HYPERLINK "http://deolhonacapital.blogspot.com.br/2008/05/para-queserve-um-jornal.html\%20Acesso\%20em:\%20\%202"

4. Cereja WR, Cochar MTA. Português: linguagens: literatura, gramática e redação. 2. ed. rev. e ampl. São Paulo: Atual, 1994.

5. Dicionário Aurélio online. Dicionário de Português. [citado 2017 Abril 23]. Disponível em: https://dicionariodoaurelio.com/jornais

6. Felício FOB. Linguagem verbal e não-verbal. Secretaria de Educação do Paraná, Curitiba, 2016. [citado 2017 Abril 10]. Disponível em: http://www.portugues.seed.pr.gov.br/modules/conteudo/conteudo.php?conteudo=719

7. Marques RJ. Comunicação verbal e não verbal. [citado 2017 Abril 23]. Disponível em: http://www.jrmcoaching.com.br/blog/comunicacao-verbal-e-nao-verbal/

8. Ribeiro WFP. Escola de Enfermagem Wenceslau Braz: da Santa Casa de Misericórdia de Itajubá à Congregação das Irmãs da Providencia de GAP (Itajubá, 1953-1959) Rio de Janeiro: Universidade Federal do Rio de Janeiro; 2007.

9. Rosa GT. Noticiabilidade e imagens de si: ser mulher e ser notícia em jornais direcionados para mulheres. Universidade Federal de Minas Gerais (UFMG). 2016; 1 295p. [citado 2017 Abril 10]. Disponível em:

file:///C:/Users/Acer/Downloads/tese_noticiabilidade_e_imagens_de_si_gerlice_rosa. pdf 
10. Tiburcio MLR. Notícia Histórica da Escola de Enfermagem Wenceslau Braz. Rev Bras Enferm1965;18:144-150.

11. Uma escola de enfermagem na região sul-mineira. Diário de Poços de Caldas, Poços de Caldas: ano XI, n.2.890, 28 dez 1954.

12. Escola de Enfermagem Wenceslau Braz. O Sul de Minas, Itajubá, 1955.

13. Escola de Enfermagem Wenceslau Braz. O Sul de Minas, Itajubá, 1956.

14. Escola de Enfermagem Wenceslau Braz. O Sul de Minas, Itajubá, 1957.

15. Formatura da $1^{\underline{a}}$ turma. O Sul de Minas, Itajubá, 1958.

16. Preito de reconhecimento e admiração. O Sul de Minas, Itajubá, 1957.

17. Escola de Enfermagem Wenceslau Braz, solenidade de formatura de sua 1a. turma. $O$ Sul de Minas, Itajubá, 1958. 